\title{
Peran Public Relations dalam Film Hancock
}

\author{
The Role of Public Relations in The Hancock FiLm
}

\author{
${ }^{1}$ Muhammad Reyzha Noorsyam Arkiang, ${ }^{2}$ M. Subur Drajat, ${ }^{3}$ Dadi Ahmadi \\ 1,,3 2 Prodi Ilmu Hubungan Masyarakat, Fakultas Ilmu Komunikasi, Universitas Islam Bandung, \\ Jl. Tamansari No.1 Bandung 40116 \\ email: ${ }^{1}$ reyzhaarkiang@gmail.com, ${ }^{2}$ mohammad.subur@unisba.ac.id, ${ }^{3}$ dadiahmadi@gmail.com
}

\begin{abstract}
Film is a mass media that has a function as entertainment, besides that the film also contains an informative, educative, and persuasive function. Film is also known as a medium of communication, film is an effective means to shape the perspective of society at large. A movie titled "Hancock" is a movie about a public relations practitioner who tries to restore the image of a superhero. This movie also tells a story about the troublesome life of a superhero who has bad image in the eyes of public and media. The purpose of this research is to understand the Reality Level, Representation Level and Ideology Level of public relations role in the movie "Hancock". The research method is using the qualitative methods with semiotics approach, which is a science about signs. The theory used is John Fiske's theory of Television Codes which focuses on the Reality Level, Representation level and Ideology Level. In this research the data collection techniques used are observation, documentation, literature study, and interviews. The results of this study conclude that at the reality level it is seen in the form of behavior and appearance which includes expert advisors who provide input, problem solvers in crisis, media relations, providers as well as media relations, communication technicians, public tranquilizers, and case development informants. showed that the role of public relations and Ray Embrey's Appearance tended to be stable when meeting with the public and Hancock as management, namely by using formal equipment in the form of shirts, suits, ties, material trousers and loafers. At the level of representation in the form of a camera code and dialogue code which includes, Framing with Background, Group Shot, Walking Shot, Two Shot, Three Shot, Eye Level, and, Point of View Shot and dialog used by Ray Embrey in this film too very shows the role of public realtions that show that it is an expert communicator and expert advisor by persuasive communication. At the ideological level, there was an ideology that appeared in the Hancock film with discrimination between white and black race and based on the eighth point of the Public Relations International code of ethics. The suggestion for further research is to look for references to books related to semiotics and the role of public relations. This is needed to be able to better understand the forms of the role of public relations in a film.
\end{abstract}

\section{Keywords: Mass Media, Reality, Semiotic, Television Codes, John Fiske}

\footnotetext{
Abstrak. Film merupakan media massa yang memiliki fungsi sebagai hiburan, disamping itu juga film mengandung fungsi informatif, edukatif, dan persuasif. Film juga dikenal sebagai media komunikasi, film merupakan salah satu sarana yang efektif untuk membentuk perspektif masyarakat secara luas. Film "Hancock" merupakan sebuah film yang mengangkat kisah tentang perbaikan citra dari seorang pahlawan oleh seorang praktisi public relations. Film ini juga mengangkat persoalan kehidupan seorang pahlawan yang memiliki citra buruk di mata publik dan media. Tujuan dari penelitian ini adalah untuk mengetahui bagaimana level realitas, level representasi, dan level ideology peran public relations dalam film "Hancock". Metode penelitian yang digunakan oleh peneliti adalah metode kualitatif dengan pendekatan semiotika, yaitu suatu ilmu yang mengkaji tentang tanda-tanda. Teori
} 
yang digunakan adalah kode-kode televisi John Fiske dimana memfokuskan pada level Realitas, level Representasi, dan level Ideologi. Pada penelitian ini teknik pengumpulan data yang digunakan berupa observasi, dokumentasi, studi pustaka, dan wawancara. Hasil dalam penelitian ini menyimpulkan bahwa pada level realitas terlihat dalam bentuk perilaku dan penampilan yang meliputi penasihat ahli yang memberikan masukan, pemecah permasalahan ketika dalam krisis, media relations, penyedia juga penyalur hubungan dengan media, teknisi komunikasi, penenang publik, dan informan perkembangan kasus yang menunjukan bahwa adanya peran public relations dan Penampilan Ray Embrey, cenderung stabil ketika bertemu dengan publik dan Hancock sebagai manajemen, yaitu dengan menggunakan stelena formal berupa kemeja, jas, dasi, celana panjang bahan, dan sepatu pantofel. Pada level representasi dalam bentuk kode kamera dan kode dialog yang meliputi, Framing with Background, Group Shot, Walking Shot, Two Shot, Three Shot, Eye Level, dan, Point of View Shot dan dialog yang di gunakan oleh Ray Embrey dalam film ini juga sangat menunjukan peran public realtions yang menunjukan bahwa ia merupakan seorang expert communicator dan penasihat ahli dengan melakukan komunikasi persuasif. Pada level ideologi terlihat adanya Ideologi yang muncul dalam film Hancock terdapat diskriminasi Ras antara kulit putih dengan Ras kulit hitam dan berdasarkan kode etik Public Relations Internasional point ke delapan. Adapun saran untuk penelitian selanjutnya adalah lebih mencari referensi buku terkait dengan semiotika dan peran public relations. Hal ini diperlukan untuk dapat lebih memahami bentuk-bentuk peran public relations dalam sebuah film.

Kata kunci: Media Massa, Realitas, Semiotika, Kode-kode Televisi, John Fiske

\section{Pendahuluan}

Film "Hancock" merupakan salah satu film drama komedi karya Peter Berg yang berdurasi 92 menit, berhasil meraup untung sekitar 624.4 miliyar dolar. Film yang di produksi pada tahun 2008 ini bercerita mengenai seorang pria yang memiliki kekuatan super yang bernama John Hancock yang dperankan oleh Will Smith dan sering membantu orang-orang, namun pria tersebut seorang pemabuk dan seseorang yang brengsek, karena memiliki sifat yang buruk, sehingga masyarakat malah membenci dan berkata bahwa pertolongan dari pria tersebut membuat kerugian yang besar. Ketika melihat hal tersebut seorang Public relations, bernama Ray Embrey yang diperankan oleh Jason Bateman, melihat permasalahan dari Hancock dan menawarinya untuk menyelasiakan masalahnya.

Dalam film "Hancock" Ray Embrey menawarkan jasanya sebagai seorang public relations kepada Hancock untuk mengubah pandangan publik atau citra dari Hancock agar dapat diterima dengan baik oleh masyarakat dan mengubah cara Hancock menampilkan diri dihadapan publik. Peran yang ditunjukan oleh public relations di dalam film ini ada beragam disetiap strategi yang digunakannya untuk mengembalikan citra dari Will Smith, salah satunya adalah meneyerahkan diri untuk mengikuti pengadilan dan mengadakan press release yang memberikan permintaan maaf dan pernyataan kepada publik bahwa Will Smith akan menjalani terapi alkohol dan amarah,

Permasalahan tersebut, berkaitan dengan definisi Public relations dari Howard Bonham yang dikutip oleh Neni Yulianita dalam bukunya yang berjudul Dasar-Dasar Public Relations yang mengatakan "Public relations is the art of bringing about better public understanding which breeds greater 
public confidence for any individual or organization.” (Yulianita, 2012: 27).

Bonham mendefinisikan public relations adalah seni untuk menciptakan pengertian publik secara lebih baik, sehingga dapat memperdalam kepercayaan seseorang atau organisasi. Hal yang dimaksud seni dalam definisi tersebut adalah seni yang berkaitan dengan komunikasi, dimana seorang public relations harus mampu menampilkan seni berkomunikasi yang baik sehingga akan memberikan keuntungan pada nama baik seseorang atau organisasi. Prinsip dasar dari seni berkomunikasi adalah untuk dapat menarik minat publik dan memperdalam kepercayaan publik terhadap segala hal yang berkaitan dengan seseorang atau organisasi.

Dalam penelitian ini, peneliti mengambil objek penelitian berupa peran public relations yang terdapat pada film Hancock, karena dirasa mengandung banyak peran public relations di dalamnya. Dalam film Hancok pun menampilkan seorang praktisi public relations dan juga memfokuskan terhadap praktisi public relations tersebut untuk menyelesaikan masalah seorang pahlawan yang memiliki citra yang buruk, adanya seorang public relations yang ditampilkan untuk menyelesaikan masalah mengenai citra maka, dalam film tersebut dipastikan memiliki unsur peran public relations.

\section{Landasan Teori}

Public relations adalah falsafah dan fungsi manajemen yang diekspresikan melalui kebijaksanaan dan kegiatan-kegiatan untuk melayani kepentingan publik, melakukan kegiatan komunikasi bagi publiknya untuk menciptakan pengertian dan goodwill dari publiknya. Dengan demikian pengertian public relations jika dilihat dan diterjemahkan dari asal katanya adalah "Hubungan hubungan antar Publik" atau singkatnya "Hubunganhubungan publik".

Dalam buku Rosady Ruslan (2014: 12), Onong Uchjana Effency mengungkapkan peranan public relations, yaitu mencakup bidang yang luas menyangkut hubungan dengan berbagai pihak dan tidak hanya sekedar berbentuk relations dalam arti sempit, karena personal relations mempunyai peranan yang cukup besar dalam melakukan kampanye public relations . Bagaimana meningkatkan kesadaran, pengertian, dan pemahaman tentang aktivitas perusahaan atau lembaga termasuk membentuk sikap baik (favorable), itikad baik (good will), toleransi (tolerance), saling pengertian (mutual understanding), saling mempercayai (mutual confidence), saling menghargai (mutual appreciation), yang pada akhirnya menciptakan citra yang baik. Menurut pengertian peranan tersebut maka peranan merupakan menjadi bagian terpenting untuk seseorang public relations. . Menurut pengertian peranan tersebut maka dibagi menjadi empat kategori yaitu, Penasihat Ahli (Expert Prescriber), Fasilitator Komunikasi (Communication Fasillitator), Fasilitator Proses Pemecahan Masalah (Problem Solving Process Fasillitator), dan Teknisi Komunikasi (Communication Technician).

Menurut John Fiske, semiotika adalah studi tentang pertanda dan makna dari siste tanda; ilmu tentang tanda, tentang bagaimana makna dibangun di dalam "teks" media; atau studi tentang bagaimana randa dari jenis karya apa pun dalam masyarakat yang mengkomunikasiakan makna.

The Codes of Televison menurut Fiske, kode-kode yang muncul atau yang digunakan dalam acara televisi saling berhubungan sehingga terbentuk sebuah makna. Menurut teori ini pula, sebuah 
realitas tidak muncul begitu saja melalu kode-kode yang timbul, namun juga diolah melalui penginderaan sesuai referensi yang telah dimiliki oleh pemirsa televisi, sehingga sebuah kode akan dipersepsi secara berbeda oleh orang yang berbeda juga. The Codes of Television terdiri dari tiga level yaitu, Level Realitas, Level Representasi, Level Ideologi.

\section{Hasil Penelitian dan Pembahasan}

\section{Analisis Level Realitas}

Pada level ini terdapat tiga kode, yaitu : Perilaku (Behavior), Penampilan (Apperance), dan Dialog (Speech).

Dalam scene satu tersebut peneliti menemukan temuan bahwa peran public relations di dalam film Hancock ini peneliti menemukan bahwa peran public relations dalam scene satu film Hancock ini sebagai expert communicator dan sebagai penenang publik. Ketika publik marah terhadap Hancock, disana seorang public relations berperan sebagai penenang dan sebagai expert communicator.

Pada scene kedua, Peneliti menemukan bahwa pada scene dua tersebut Ray Embrey berperan sebagai media relations. Pada dasarnya Ray Embrey melalukan identifikasi media untuk mencari tahu akibat perbuatan Hancock sehingga timbul kasus yang menimpa Hancock dengan cara menganalisis pemberitaan media, lalu selanjutnya adalah analisis media untuk lebih memastikan bahwa krisis yang dialami adalah benar. Disamping itu peran public relations yang terlihat pada scene dua adalah sebagai penasihat ahli dan sebagai fasilitator proses pemecahan masalah. Pada scene ketiga, peran public relations yang berupa fasilitator komunikasi dalam hal ini, praktisi public relations bertindak sebagai komunikator atau mediator untuk membantu pihak manajemen dalam hal untuk mendengar apa yang diinginkan dan diharapkan oleh publiknya. Terdapat juga peran public relations sebagai teknisi komunikasi, berbeda dengan tiga peranan praktisi public relations professional sebelumnya yang terkait erat dengan fungsi dan peranan manajemen organisasi.

Pada scene keempat, peran public relations yang terlihat adalah sebagai penasihat ahli, Terlihat pada saat Hancock akan meninggalkan penjara, Ray Embrey langsung berusaha menahannya dengan komunikasi yang persuasif sehingga Hancock pun berubah pikiran. Cara Ray Embrey untuk merubah pikiran Hancock dapat dikatakan sebagai seorang penasihat ahli.

Pada scene kelima, peran public relations yang terlihat merupakan penasihat ahli terlihat ketika Ray Embrey menjelaskan bagaimana cara Hancock tampil dihadapan publik.

Kode kedua dari level realitas yaitu penampilan (appearance). Ray Embrey sebagai praktisi public relations, selalu menggunakan pakaian rapih dan formal ketika di hadapan publik dan bertemu dengan Hancock.

Pada scene pertama terlihat bahwa Ray Embrey menggunakan kemeja berwarna putih, jas berwarna hitam, dasi berwarna hitam, dan sepatu pantofel hitam. Selain itu juga terlihat rambut dari Ray Embrey yang terlihat rapih.

Pada scene kedua terlihat menggunakan kemeja berwarna hitam, celana panjang berwana hitam, dan sepatu pantofel. Pada scene ini Ray Embrey bertemu dengan Hancock secara informal di rumah Ray Embrey, namun Ray Embrey tetap menggunakan pakaian yang rapih untuk menunjukan 
profesionalitas nya sebagai seorang public relations.

Pada scene ketiga terlihat Ray Embrey menggunakan kemeja berwarna putih, dasi berwarna hitam, jas berwana hitam, celana panjang berwarna hitam, dan sepatu pantofel. Dimana ketika dalam kegiatan resmi seperti press conference Ray Embrey menjaga penampilannya.

Pada scene keempat terlihat Ray Embrey menggunakan kemeja berwarna hitam, jas berwarna hitam, celana panjang berwarna hitam, dan sepatu pantofel. Ray Embrey sebagai public relations menunjukan citranya saat di hadapan publik yang kecil seperti di kantor polisi tetap menampilkan penampilan yang baik.

\section{Analisis Level Representasi}

Pada level ini terdapat kode yaitu kode kamera dan kode dialog. Kode kamera yang diambil melalui berbagai macam teknik pengambilan gambar ini untuk memperjelas alur cerita dalam film sehingga pesan yang terkandung didalamnya dapat tersampaiakn dengan baik kepada penonton.

Pada scene pertama, Kode kamera yang terlihat ketika Ray Embrey menjadi fokus objek dan di belakangnya publik merupakan kode kamera, Framing with Background yang tujuan teknik pengambilan gambar ini sebetulnya memberi efek keindahan. ). Setelah itu pengambilan gambar yang terlihat adalah Group Shot yaitu, pengambilan gambar sekelompok orang. Sedangkan ketika Ray Embrey berjalan menuju kedalam kerumunan kode kamera yang terlihat adalah Walking Shot, sesuai dengan namanya, teknik ini mengambil gambar pada objek yang sedang berjalan.

Pada scene kedua, Kode kamera yang terlihat ketika percakapan antara Ray Embrey dan Hancock adalah Two Shot yaitu, pengambilan gambar dua orang. Setelah itu kode kamera yang terlihat Setelah itu kode kamera yang terlihat seakan-akan menjadi mata dari Hancock yang sedang melihat televisi merupakan kode kamera Eye Level yang artinya, sudut pengambilan gambar sejajar dengan objek. Terakhir kode kamera yang terlihat merupakan kode kamera Three Shot yaitu, pengambilan gambar tiga orang.

Pada scene ketiga, terlihat kode kamera Point of Views Shot yakni, memperlihatkan shot dalam posisi sedang ngobrol resmi kamera akan bergantian mengambil close up objeknya. Selanjutnya ketika pengambilan gambar pada Ray Embrey kode kamera yang terliaht adalah Framing with Background yang tujuan teknik pengambilan gambar ini sebetulnya memberi efek keindahan. Terakhir kode kamera Group Shot yaitu, pengambilan gambar sekelompok orang.

Pada scene keempat, kode kamera yang terlihat pada scene ini adalah Two Shot yaitu, pengambilan gambar dua orang. Fungsinya untuk memperlihatkan adegan dua orang sedang bercakap.

Pada scene kelima, pada scene kelima ini juga memperlihatkan dari awal samapi akhir scene kode kamera Two Shot yaitu, pengambilan gambar dua orang. Fungsinya untuk memperlihatkan adegan dua orang sedang bercakap.

Kode kedua dari level representasi adalah dialog (dialogue)). Dalam setiap scene nya Ray Embrey memperlihatkan peranannya sebagai expert prescriber kepada Hancock.

Pada scene pertama Dalam dialog yang disampaikan Ray Embrey kepada publik terlihat jelas bahwa Ray Embrey mencoba membela Hancock dari serangan publik dan mencoba merubah perilaku dari publik yang marah. 
Pada scene kedua, Ray Embrey berdialog dengan Hancock untuk mencoba memberitahu apa yang menjadi permasalahan dari Hancock dan berusaha meyakinkan Hancock.

Pada scene ketiga, Pada scene ini
Pada scene kelima, Dialog pada scene ini menunjukan Ray Embrey yang mencoba mengajarkan bagaimana harus bersikap didalam publik untuk mendapatkan simpati dari publik itu sendiri.

Tabel 1. Hasil Penelitian

\begin{tabular}{|c|c|c|c|c|}
\hline No. & Scene & Level Realitas, & Level Representasi & Level Ideology \\
\hline \multirow[b]{2}{*}{1.} & \multirow[b]{2}{*}{$\begin{array}{l}\text { Menit } \\
17: 00\end{array}$} & $\begin{array}{l}\text { Sebagai expert communicator dan sebagai penenang publik, } \\
\text { Ketika publik berwasalab dengan. pavajemen, disana seorang } \\
\text { public relations berperan sebagai penenang dan sebagai expert } \\
\text { communicator. }\end{array}$ & $\begin{array}{ll}\text { - } & \text { Group Shot } \\
\text { - } & \text { Walking Shot } \\
\text { - } & \text { Framing with Background }\end{array}$ & \multirow[t]{2}{*}{$\begin{array}{l}\text { Diskrimoinasi Ras } \\
\text { antara kulit bitam } \\
\text { dan kulit putib. }\end{array}$} \\
\hline & & $\begin{array}{l}\text { sebagai praktisi public relations, selalu menggunakan pakaian } \\
\text { rapib dan formal ketika di badapan publik dan bertemu dengan } \\
\text { klien. }\end{array}$ & 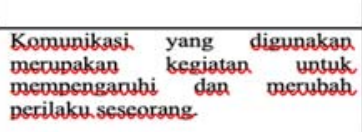 & \\
\hline \multirow[t]{2}{*}{2.} & \multirow[t]{2}{*}{$\begin{array}{l}\text { Menit } \\
28: 19\end{array}$} & 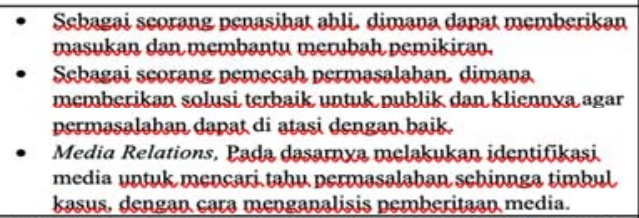 & $\begin{array}{ll}- & \text { Two Shot } \\
\text { - } & \text { Three Shot } \\
\text { Eye Level }\end{array}$ & \multirow[t]{2}{*}{ 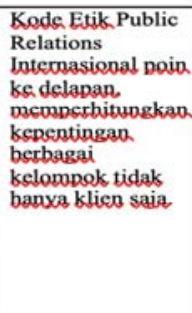 } \\
\hline & & $\begin{array}{l}\text { sebagai praktisi public relations, selalu mengguvakan pakaian } \\
\text { rapib. dan formal ketika di badanan publik dan bertemu dengan. } \\
\text { klien. }\end{array}$ & $\begin{array}{l}\text { Komunikasi yang digunakan } \\
\text { mecupakan kegjatan untuk } \\
\text { mempengacubi dan merubah } \\
\text { Derilaku seseorang. }\end{array}$ & \\
\hline \multirow{2}{*}{3.} & \multirow{2}{*}{$\begin{array}{l}\text { Menit } \\
32: 10\end{array}$} & 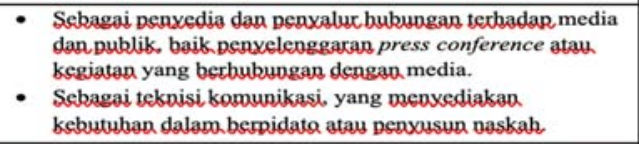 & $\begin{array}{l}\text { - } \quad \text { Point of View Shot } \\
\text { - } \quad \text { Framing with Background } \\
\text { - Group Shot }\end{array}$ & \multirow[b]{2}{*}{ - } \\
\hline & & $\begin{array}{l}\text { sebagai praktisi public relations, selalu mengguoakan pakaian } \\
\text { rapib. dan formal ketika di badapan publik dan bertemu dengan } \\
\text { klien. }\end{array}$ & $\begin{array}{l}\text { Komunikasi yang digunakan } \\
\text { mecupakan kegjatan untuk } \\
\text { penpengabiai dan menubah } \\
\text { perilaku seseorang. }\end{array}$ & \\
\hline \multirow{2}{*}{4.} & \multirow{2}{*}{$\begin{array}{l}\text { Menit } \\
35: 41\end{array}$} & $\begin{array}{l}\text { - Sebagai seorang penasibat abli. dimana dapat memberikan } \\
\text { masukan dan membantu merubah pemikitan. } \\
\text { - Sebagai informan. Rerkembangan Kasus yang } \\
\text { mempresentasikan keadaan yang sedang dijalani. }\end{array}$ & - Two Shot & \multirow{2}{*}{ - } \\
\hline & & $\begin{array}{l}\text { sebagai praktisi public relations, selalu menggunakan pakaian } \\
\text { rapib. dan formal ketika di badapan publik dan bertemu dengan. } \\
\text { klien. }\end{array}$ & $\begin{array}{l}\text { Komunikasi yang digunakan } \\
\text { merumakan kegiatan untuk } \\
\text { mempengarubi dan merubah } \\
\text { perilaku seseorang. }\end{array}$ & \\
\hline \multirow[b]{2}{*}{5.} & \multirow[b]{2}{*}{$\begin{array}{l}\text { Menit } \\
38: 18\end{array}$} & $\begin{array}{l}\text { - Scbagai seorang penasibat abli dimana dapat memberikan } \\
\text { masukan dan membantu mecubah pemikitan. }\end{array}$ & - Two Shot & \multirow[b]{2}{*}{ - } \\
\hline & & $\begin{array}{l}\text { sebagai praktisi public relations, selalu menggupakan pakaian } \\
\text { rapib dan formal ketika di badapan publik dan bertemu dengan } \\
\text { klien. }\end{array}$ & $\begin{array}{l}\text { Komunikasi yang digunakan } \\
\text { merupakan kegiatan untuk } \\
\text { mempengarubi dan merubah } \\
\text { nerilaku. seseorang. }\end{array}$ & \\
\hline
\end{tabular}

tidak ada dialog yang dikatakan oleh Ray Embrey secara langsung, namun secara tidak langsung dialog yang dikatakan oleh Hancock merupakan buah pikir dari Ray Embrey yang berupaya untuk mempengaruhi publik.

Pada scene keempat, Pada scene ini dialog dari Ray Embrey adalah untuk memberitahukan perkembangan sstrategi dan juga membujuk Hancock untuk tetap berjalan dalam strategi yang telah dijalankan.

INTER KOMUNIKA Jurnal Komunikasi DOI: http://dx.doi.org/10.33376/ik.v3i2.214

\section{Analisis Level Ideology}

Pada scene pertama, terlihat bahwa ada sebuah ideologi yang ditampilkan merupakan sebuah diskrimanasi Ras antara kulit hitam dan kulit putih, dimana diperlihatkan Ray Embrey dipernakan dalam orang kulit putih sedangkan Hancock dipernakan sebagai orang kulit hitam.

Pada scene kedua, Dalam scene kedua terdapat sebuah ideologi yang disampaikan oleh Ray Embrey yang 
pada intinya mendorong Hancock untuk mengikuti keinginan publik dan pada saat yang bersamaan membuat publik sadar bahwa Hancock memiliki pengaruh yang cukup besar bagi masyarakat.

\section{Kesimpulan}

Peran public relations yang ada didalam film Hancock tergambar melalui kode-kode visual John Fiske antara lain :

1. Level Realitas

- Perilaku : perilaku Ray Embrey selaku public relations pada film Hancock yang dapat menjalankan sebagai penasihat ahli yang memberikan masukan, pemecah permasalahan ketika dalam krisis, media relations, penyedia juga penyalur

- hubungan dengan media, teknisi komunikasi, penenang publik, dan informan perkembangan kasus yang menunjukan bahwa adanya peran public relations.

- Penampilan : penampilan Ray Embrey, cenderung stabil ketika bertemu dengan publik dan Hancock sebagai manajemen, yaitu dengan menggunakan stelena formal berupa kemeja, jas, dasi, celana panjang bahan, dan sepatu pantofel.

\section{Level Representasi}

- Kode Kamera : berbagai teknik pengambilan gambar dalam film Hancock tidak memiliki perbedaan dengan film lainnya. Pengambilan gambar yang terlihat yaitu, Framing with background, Group shot, Walking Shot, Two Shot, Three Shot, Eye Level, dan Point of View Shot.
- Dialog : Dialog yang di gunakan oleh Ray Embrey dalam film ini juga sangat menunjukan peran public realtions yang menunjukan bahwa ia merupakan seorang expert communicator dan penasihat ahli dengan melakukan komunikasi persuasif.

3. Level Ideologi

Ideologi yang muncul dalam film Hancock terdapat diskriminasi Ras antara kulit putih dengan Ras kulit hitam dan pada peran public relations Ray Embrey adalah bahwa Ray Embrey memiliki ideologi bahwasannya seorang public relations harus bertindak, pada segala keadaan, untuk memperhitungkan kepentingan kelompok-kelompok yang terlibat, baik kepentingan organisasi yang dia layani dan kepentingan yang berhubungan dengan publik.

\section{Saran}

\section{Saran Teoritis}

Dengan hasil penelitian yang telah peneliti dapatkan, di sarankan khususnya untuk mahasiswa Universitas Islam Banduung fakultas ilmu komunikasi, agar dapat meneruskan penelitian serupa mengenai peran public relations dalam film secara lebih lanjut. Diharapkan juga agar yang melakukan penelitian sejenis dapat mengambil variable penelitian yang berbeda, atupun dengan menggunakan variasi metode yang berbeda dari yang digunakan peneliti sehingga dapat menjelaskan berbeda dengan penelitian yang telah diteliti oleh peneliti. 


\section{Saran Praktis}

Secara praktis, hasil penelitian ini diharapkan dapat memberikan masukan khususnya mahasiswa, untuk lebih mengetahui dan memahami mengenai peran public relations yang ada di dalam sebuah film karena dirasa penting untuk mengetahui isi pesan dalam sebuah komunikassi massa, karena juga sebuah film merupakan media pembelajaran. Sehingga setiap orang khususnya mahasiswa dapat mengetahui bagaimana cara memandang atau menganalisis pesan yang berada di dalam sebuah film melalui berbagai level, dan tidak hanya menjadi sarana hiburan namun juga menjadi sarana pembelajaran yang mencerdaskan masyarakat.

\section{Daftar Pustaka}

Moleong, Lexy, J. 2011. Metodologi Penelitian Kualitatif. Bandung: PT. Remaja Rosdakarya

Mulyana, Deddy. 2014. Ilmu Komunikasi: Suatu Pengantar. Bandung: PT. Remaja Rosdakarya.

Ruslan, Rosady. 2008. Manajemen Public Relations dan Media Komunikasi.Jakarta :Rajawali Pers Vera, Nawiroh. 2014. Semiotika dalam Riset Komunikasi. Bogor: Ghalia Indonesia

Sobur, Alex. 2017. Semiotika Komunikasi. Bandung: PT. Remaja Rosdakarya

Yulianita, Neni. 2012. Dasar-Dasar Public Relations. Bandung: P2ULPPM UNISBA. 